\title{
Diagnostic accuracy of CT pulmonary angiography in suspected pulmonary hypertension
}

\author{
Andrew J. Swift ${ }^{1,2,3} \cdot$ Krit Dwivedi $^{1}$. Chris Johns ${ }^{1}$ • Pankaj Garg ${ }^{1} \cdot$ Matthew Chin ${ }^{1}$ • Ben J Currie ${ }^{1}$ - Alex MK Rothman ${ }^{1}$. \\ Dave Capener $^{1}$ - Yousef Shahin ${ }^{1}$. Charlie A Elliot ${ }^{4}$. Thanos Charalampopolous ${ }^{4}$ - Ian Sabroe ${ }^{1,4}$. Smitha Rajaram ${ }^{5}$. \\ Catherine Hill $^{5} \cdot \operatorname{Jim}$ M. Wild ${ }^{1,2} \cdot$ Robin Condliffe $^{4} \cdot$ David G. Kiely ${ }^{2,4}$
}

Received: 3 October 2019 / Revised: 23 December 2019 / Accepted: 30 March 2020 / Published online: 27 April 2020

(C) The Author(s) 2020

\begin{abstract}
Objectives Computed tomography (CT) pulmonary angiography is widely used in patients with suspected pulmonary hypertension $(\mathrm{PH})$. However, the diagnostic and prognostic significance remains unclear. The aim of this study was to (a) build a diagnostic $\mathrm{CT}$ model and (b) test its prognostic significance.

Methods Consecutive patients with suspected $\mathrm{PH}$ undergoing routine CT pulmonary angiography and right heart catheterisation (RHC) were identified. Axial and reconstructed images were used to derive CT metrics. Multivariate regression analysis was performed in the derivation cohort to identify a diagnostic $\mathrm{CT}$ model to predict $\mathrm{mPAP} \geq 25 \mathrm{mmHg}$ (the existing ESC guideline definition of $\mathrm{PH}$ ) and $>20 \mathrm{mmHg}$ (the new threshold proposed at the 6th World Symposium on PH). In the validation cohort, sensitivity, specificity and compromise CT thresholds were identified with receiver operating characteristic (ROC) analysis. The prognostic value of the CT model was assessed using Kaplan-Meier analysis.

Results Between 2012 and 2016, 491 patients were identified. In the derivation cohort $(n=247)$, a CT model was identified including pulmonary artery diameter, right ventricular outflow tract thickness, septal angle and left ventricular area. In the validation cohort $(n=244)$, the model was diagnostic, with an area under the ROC curve of $0.94 / 0.91$ for mPAP $\geq 25 />$ $20 \mathrm{mmHg}$ respectively. In the validation cohort, 93 patients died; mean follow-up was 42 months. The diagnostic thresholds for the CT model were prognostic, log rank, all $p<0.01$.

Discussion In suspected PH, a diagnostic CT model had diagnostic and prognostic utility.

Key Points

- Diagnostic CT models have high diagnostic accuracy in a tertiary referral population of with suspected PH.

- Diagnostic CT models stratify patients by mortality in suspected PH.
\end{abstract}

Keywords Hypertension, pulmonary $\cdot$ Pulmonary artery $\cdot$ Heart ventricles $\cdot$ Diagnostic imaging

Abbreviations

ASPIRE Assessing the spectrum of PH identified at a referral centre
CMR Cardiac magnetic resonance

CTEPH Chronic thromboembolic PH

CTPA Computerised tomography pulmonary angiogram

Electronic supplementary material The online version of this article (https://doi.org/10.1007/s00330-020-06846-1) contains supplementary material, which is available to authorized users.

Andrew J. Swift

a.j.swift@shef.ac.uk

1 Department of Infection, Immunity and Cardiovascular Disease, University of Sheffield, Sheffield, UK

2 INSIGNEO, Institute for In Silico Medicine, University of Sheffield, Sheffield, UK
3 Academic Unit of Radiology, University of Sheffield, C Floor, Royal Hallamshire Hospital, Glossop Road, Sheffield S10 2JF, UK

4 Sheffield Pulmonary Vascular Disease Unit, Royal Hallamshire Hospital, Sheffield Teaching Hospitals NHS Foundation Trust, Sheffield, UK

5 Radiology Department, Sheffield Teaching Hospitals NHS Foundation Trust, Sheffield, UK 


$\begin{array}{ll}\text { ICC } & \text { Intra-class correlation co-efficient } \\ \text { MRI } & \text { Magnetic resonance imaging } \\ \text { PA } & \text { Pulmonary artery } \\ \text { PAH } & \text { Pulmonary artery hypertension } \\ \text { PH } & \text { Pulmonary hypertension } \\ \text { Q-Q } & \text { Quantile-quantile } \\ \text { RHC } & \text { Right heart catheter } \\ \text { ROC } & \text { Receiver operating characteristic }\end{array}$

\section{Introduction}

Pulmonary hypertension $(\mathrm{PH})$ has been defined arbitrarily as a mean pulmonary artery pressure of at least $25 \mathrm{mmHg}$ at rest [1]. However, data from normal subjects have suggested that a mean pulmonary artery pressure in excess of $20 \mathrm{mmHg}$ is abnormal [2]. The 6th World Symposium on PH has therefore proposed a threshold of $>20 \mathrm{mmHg}$ to define $\mathrm{PH}$ and a requirement for a pulmonary vascular resistance of at least 3 Wood Units to define pre-capillary PH. PH has many causes and its presence is associated with a high morbidity and a high mortality [3]. Due to the non-specificity of symptoms, $\mathrm{PH}$ is often diagnosed late. Given the availability of therapies for specific forms of $\mathrm{PH}$, there is increasing interest in better patient phenotyping and improving diagnostic rates with imaging [4].

Transthoracic Doppler echocardiography is a non-invasive test, which is widely available, is relatively inexpensive and is recommended in international guidelines if the diagnosis of $\mathrm{PH}$ is suspected [1]. In a meta-analysis of diagnostic studies, the pooled sensitivity for the diagnosis of $\mathrm{PH}$ was $88 \%$ (8492) and specificity was $56 \%$ (46-66) [5]. In patients with obesity or lung disease, views of the tricuspid regurgitant jet and cardiac chambers may be inadequate [6,7]. A recent study has shown that, in a large population of patients undergoing echocardiography, tricuspid regurgitant jet velocity can be measured in 50\% of patients [8]. More recently, there has been interest in the role of MRI techniques to identify patients with $\mathrm{PH}$ and a number of features visible on MRI such as elevated ventricular mass index [9-11], reduced pulmonary artery pulsatility $[12,13]$ and pulmonary flow $[14,15]$ may suggest the diagnosis of PH. However, MRI is expensive and less available than other imaging modalities. Right heart catheterisation (RHC) is the gold standard test for pressure measurement and thus diagnosis of $\mathrm{PH}$.

Computed tomography has been seen to have several technological advances over the last three decades, and the introduction of iterative reconstruction $\mathrm{CT}$ algorithms has led to a significant reduction in image noise and radiation dose [16]. CT is frequently used in the evaluation of breathlessness and in the assessment of lung and increasingly cardiac disease [17-24]. The majority of studies using CT as a diagnostic tool have concentrated primarily on pulmonary artery size. However, remodelling of the cardiac chambers and bowing of the interventricular septum can also be detected on CT pulmonary angiography $[18,19,25-27]$ in patients with $\mathrm{PH}$. The aim of this study was to (a) build a diagnostic CT model in patients with suspected $\mathrm{PH}$ using the current guideline definition of $\mathrm{PH}$ ( $\mathrm{mPAP} \geq 25 \mathrm{mmHg}$ ) and the recent proposed definition of $>20 \mathrm{mmHg}$, and (b) test its prognostic significance.

\section{Materials and methods}

\section{Patients}

Consecutive treatment-naïve patients with suspected $\mathrm{PH}$ referred to a nationally designated PH centre (Sheffield Pulmonary Vascular Disease Unit) between April 2012 and March 2016 were identified from the ASPIRE Registry MRI database [28]. Inclusion criteria required CT pulmonary angiography to be performed within 90 days of RHC. All patients underwent MRI within $48 \mathrm{~h}$ of RHC. Ethical approval for this analysis of imaging techniques and routinely collected data was granted by our institutional review board.

\section{CT pulmonary angiography acquisition}

All CT pulmonary angiograms in Sheffield were performed on a light-speed 64-slice MDCT scanner (GE Healthcare). Standard acquisition parameters were used: $100 \mathrm{~mA}$ with automated dose reduction, $120 \mathrm{kV}$, pitch 1 , rotation time $0.5 \mathrm{~s}$ and $0.625 \mathrm{~mm}$ collimation. A $400 \mathrm{~mm} \times 400 \mathrm{~mm}$ field of view was used with an acquisition matrix of $512 \times 512$. One hundred millilitres of intravenous contrast agent (Ultravist, Bayer) was administered at a rate of $5 \mathrm{~mL} / \mathrm{s}$. HRCTs were reconstructed using the contrast-enhanced acquisitions with $1.25 \mathrm{~mm}$ collimation from the apex of the lung to the diaphragm. Inclusion criteria for studies performed outside of Sheffield included CT pulmonary angiography with volumetric coverage of the pulmonary vasculature and cardiac structures and reconstructed slice thickness of $2 \mathrm{~mm}$ or less.

\section{CT image analysis}

\section{Vessel measurements}

Main pulmonary artery (PA) diameter was measured perpendicular to the vessel axis at the widest point. At the same level as the main PA measurement, the diameter of the ascending and descending aorta was recorded and the pulmonary artery to aortic ratio was calculated (Fig. 1a). Right and left main pulmonary artery diameters were measured at the widest point. The IVC diameter was measured just below the entry level to the right atrium. The extent of hepatic reflux was measured using an adapted 4 grade score of regurgitation. 
Fig. 1 Multi-figure CT images illustrating the $\mathrm{CT}$ measurements in a patient with $\mathrm{PH}$ with severe elevation of pulmonary artery pressure. Illustrations show the measurement of pulmonary artery and aortic diameter (a), right ventricular outflow tract thickness (b), interventricular septal angle (c) (reconstructed short-axis images) and left ventricular area (d). Images $\mathbf{e}$ and $\mathbf{f}$ illustrate the measurements required to calculate the RV/LV diameter ratio maximal RV diameter (e) and maximal LV diameter (f)

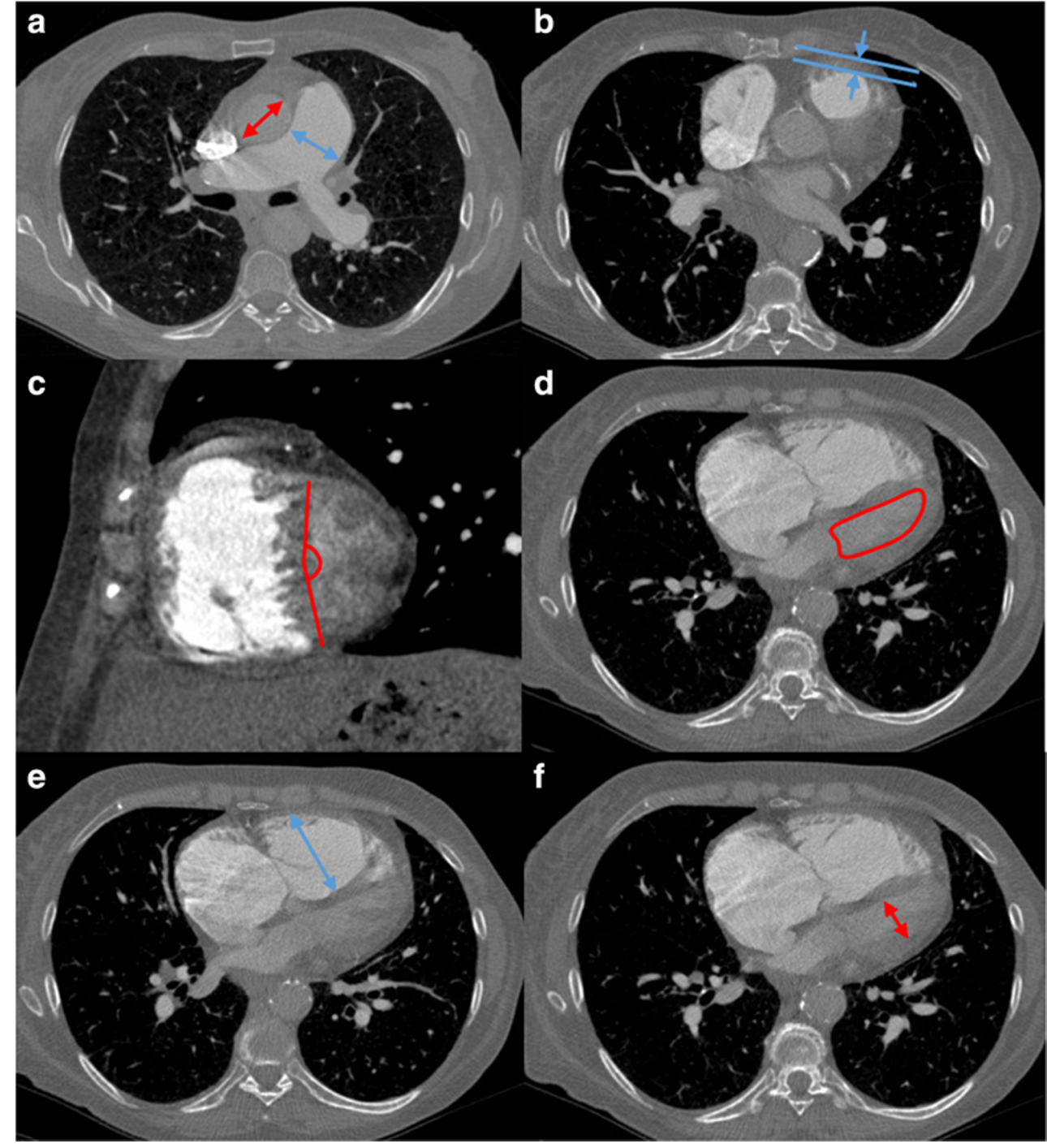

\section{Cardiac measurements}

Maximal biventricular areas and diameters (mid-ventricular) and atrial areas were manually traced on axial images. Slices were chosen to ensure the greatest area or diameter was measured. Ventricle and atrial diameters were measured on the same slices as area measurements. Ventricular muscle area and circumference walls were measured for both right and left ventricles. The muscular thickness of the RV outflow tract was measured anteriorly $\sim 1 \mathrm{~cm}$ below the pulmonary valve (Fig. 1b). Maximal LV area is shown in Fig. 1d and maximal $\mathrm{RV}$ and LV diameters are shown in Fig. 1e and f respectively.

\section{Reconstructed short-axis images}

Images were reconstructed using multi-planar reformat software (IMPAX, volume viewer, Agfa HealthCare) to generate a mid-chamber short-axis image and 4-chamber image. On the short-axis image, the interventricular septal angle was measured, defined as the angle from the RV insertion points to the mid-interventricular septum (Fig. 1c). On the reconstructed 4-chamber image, biventricular areas and diameters (mid-ventricular) and atrial areas were manually traced.

MR image acquisition and analysis methods and details on right heart catheterisation are found in the Supplementary Methods.

\section{Statistics}

Normal distribution was assessed through visual and statistical analysis, using histograms and quantile-quantile (Q-Q) plots as a way of determining normality of all variables. Where appropriate, continuous data was presented with mean and standard deviation. Group comparison of continuous data was made using independent $t$ test and categorical group comparisons was made using chi-square and Fisher's exact test. Correlations between CT measurement and mPAP, PVR and cardiac MRI data were made using Pearson's correlation test. 
Derivation and validation cohorts were identified using random number generation. CT variables significant at independent $t$ test or chi-square at univariate analysis $(p<0.05)$ in the derivation cohort were entered into a binary logistic regression model using forward stepwise selection. CT diagnostic model A was the resultant model. Sensitive, compromise and specific diagnostic thresholds were identified in the derivation cohort by visual inspection of ROC curves. In the validation cohort, the derived thresholds were tested using the $2 \times 2$ contingency table to determine sensitivity, specificity and positive and negative predictive values. A second model, CT diagnostic model $\mathrm{B}$, was developed without septal angle; septal angle is the only measurement that requires image reconstruction, and some observers will not have access to a reconstruction tool when reporting or in situations where there is limited time; therefore, we elected to develop a model that could be used on the axial images alone.

The prognostic value of CT sensitive, compromise and specific diagnostic thresholds and right heart catheterisation thresholds of $\geq 25 \mathrm{mmHg}$ and $>20 \mathrm{mmHg}$ was assessed using Kaplan-Meier and Cox proportional hazards regression analysis. The intra-class correlation co-efficient (ICC) was used to test the reproducibility of CT metrics. IBM SPSS Statistics 22 was used to perform the statistical analysis. A $p$ value of $<0.05$ was considered statistically significant.

\section{Results}

Between April 2012 and March 2016, 840 consecutive treatment-naïve patients with suspected $\mathrm{PH}$ were identified who underwent MRI and RHC, of whom 491 patients underwent CT pulmonary angiography within 90 days. Patients underwent CT imaging at 68 different institutions and 78\% of CT pulmonary angiograms were performed at the Sheffield Pulmonary Vascular Disease Unit. Patient demographics, RHC and CT metrics for patients with PH $(n=420)$, with mPAP $<25 \mathrm{mmHg}(n=71)$ and with mPAP $\leq 20 \mathrm{mmHg}$ are shown in Table 1. Patients with PH were older $(p<0.001)$ and more likely to be female $(p<0.013)$ and have a higher WHO functional class $(p<0.001)$ and lower walking distance $(p<0.001)$, than patients without PH. Correlation of CT metrics with mPAP and PVR is presented in Supplementary Table 1 and key correlations are in Fig. 2. Table 2 presents the sensitivity, specificity and positive and negative predictive value of pulmonary artery diameter, right ventricular outflow tract thickness, interventricular septal angle and RV/LV diameter ratio.

\section{Derivation cohort}

Random patient selection identified a derivation cohort of 247 and a validation cohort of 244 patients. There were no significant differences in age, proportion of patients with $\mathrm{PH}$, WHO functional class or right heart catheterisation metrics between the two cohorts $(p>0.05)$. However, there was a higher proportion of females in the derivation cohort as compared with the validation cohort (Supplementary Table 2).

\section{CT diagnostic model A}

In the derivation cohort, a regression model was identified. The model incorporated main pulmonary artery diameter, right ventricle outflow tract thickness, left ventricular area and interventricular septal angle as follows: model A score = $-14.299+(0.192 \times$ main pulmonary artery diameter, $\mathrm{mm})+$ $(0.518 \times$ right ventricle outflow tract thickness, $\mathrm{mm})-(0.001$ $\times$ left ventricular area, $\left.\mathrm{mm}^{2}\right)+(0.068 \times$ interventricular septal angle, degrees). The area under the curve (AUC) in the derivation cohort was 0.92 (see Fig. 3). The AUC in the derivation cohort with adjustment for body surface area was 0.86 . The following thresholds were identified in the derivation cohort: high sensitivity (model A score 0), high specificity (model A score 2.5) and a compromise threshold (model A score 1.25). The diagnostic model performed better than individual CT metrics. Of the individual CT metrics, the AUC for pulmonary artery diameter was 0.79 , right ventricular outflow tract thickness 0.79 , left ventricular area 0.64 and interventricular septal angle 0.84 .

For the prediction of mPAP $>20 \mathrm{mmHg}$, a model of $-13.843+(0.94 \times$ right ventricle outflow tract thickness, $\mathrm{mm})+(0.094 \times$ interventricular septal angle, degrees $)$ was identified. The diagnostic accuracy of this model was AUC 0.88 for detecting mPAP $>20 \mathrm{mmHg}$; this was of lower accuracy in comparison with model $\mathrm{A}$ that had a diagnostic accuracy of 0.90 for detecting $\mathrm{mPAP}>20 \mathrm{mmHg}$.

\section{CT diagnostic model B}

In the derivation cohort, a second model was developed; the model incorporated main pulmonary artery diameter, right ventricle outflow tract thickness and RV/LV diameter ratio, as follows: model $\mathrm{B}$ score $=-9.181+(0.174 \times$ main pulmonary artery diameter, $\mathrm{mm})+(0.480 \times$ right ventricle outflow tract thickness, $\mathrm{mm})+(2.539 \times \mathrm{RV} / \mathrm{LV}$ diameter, ratio $)$. This model had an AUC of 0.89 in the derivation cohort. The following thresholds were identified in the derivation cohort: high sensitivity (model B score 0.5 ), compromise threshold (model B score 1.0) and a high specificity threshold (model B score 1.5) (see Table 4). CT diagnostic prediction model to detect mPAP > $20 \mathrm{mmHg}$ was also derived: $-4.553+(0.661$ $\times$ right ventricle outflow tract thickness, $\mathrm{mm})+(3.027 \times \mathrm{RV} /$ LV diameter, ratio). This model had lower accuracy for prediction of mPAP $>20 \mathrm{mmHg}$ at ROC analysis: AUC 0.86 compared with 0.89 for model B. 
Table 1 Demographics of patients with and without PH for the full cohort

\begin{tabular}{|c|c|c|c|c|}
\hline Covariates & $\begin{array}{l}\text { No PH, } m P A P \leq 20 \mathrm{mmHg}, \\
n=36\end{array}$ & $\begin{array}{l}\text { No } \mathrm{PH}, \mathrm{mPAP}<25 \mathrm{mmHg} \text {, } \\
n=71\end{array}$ & $\begin{array}{l}\mathrm{PH}, \mathrm{mPAP} \geq 25 \mathrm{mmHg} \\
n=420\end{array}$ & $\begin{array}{l}p \text { value }<25 \text { vs } \\
\geq 25 \mathrm{mmHg}\end{array}$ \\
\hline \multicolumn{5}{|l|}{ Demographics } \\
\hline Age (years) & $61(14)$ & $60(15)$ & $65(13)$ & $<0.001$ \\
\hline Sex $\%$ female & & $69 \%$ & $58 \%$ & 0.013 \\
\hline $\operatorname{BSA}\left(\mathrm{m}^{2}\right)$ & $1.8(0.2)$ & $1.86(0.27)$ & $1.83(0.23)$ & 0.377 \\
\hline WHO FC \% (1/2/3/4) & $0 / 18 / 17 / 1$ & $0 / 49 / 50 / 1$ & 0/7/83/10 & $<0.001$ \\
\hline \multicolumn{5}{|l|}{ ISWT } \\
\hline Distance (m) & $346(211)$ & $315(203)$ & $206(187)$ & $<0.001$ \\
\hline \multicolumn{5}{|l|}{ RHC } \\
\hline mRAP (mmHg) & $5(3)$ & $6(3)$ & $11(6)$ & $<0.001$ \\
\hline mPAP (mmHg) & $17(2)$ & $20(3)$ & $45(13)$ & $<0.001$ \\
\hline PAWP (mmHg) & $9(5)$ & $11(5)$ & $13(5)$ & $<0.001$ \\
\hline Cardiac output (L/min) & $5.5(1.4)$ & $5.7(1.5)$ & $4.8(1.5)$ & $<0.001$ \\
\hline Cardiac index $\left(\mathrm{L} / \mathrm{min} / \mathrm{m}^{2}\right)$ & $3.0(0.8)$ & $3.1(0.8)$ & $2.6(0.8)$ & $<0.001$ \\
\hline PVR (dyns) & $120(1250)$ & $138(102)$ & $603(385)$ & $<0.001$ \\
\hline \multicolumn{5}{|l|}{ Computed tomography } \\
\hline \multicolumn{5}{|l|}{ Right heart metrics } \\
\hline RA area & 2085 (659) & $2263(1152)$ & $3108(1144)$ & $<0.001$ \\
\hline $\mathrm{RV}$ diameter $(\mathrm{mm})$ & $36(7.7)$ & $38(8.1)$ & $45(9.1)$ & $<0.001$ \\
\hline $\mathrm{RV}$ muscle wall area $\left(\mathrm{mm}^{2}\right)$ & $247(114)$ & $272(117)$ & $416(184)$ & $<0.001$ \\
\hline $\mathrm{RV}$ chamber area $\left(\mathrm{mm}^{2}\right)$ & $2084(658)$ & $2272(766)$ & 3005 (918) & 0.011 \\
\hline RV outflow tract (mm) & $4.8(1.2)$ & $4.9(1.4)$ & $7.0(1.9)$ & 0.004 \\
\hline Septal angle (degrees) & $129(7.2)$ & $132(9.5)$ & $151(14.2)$ & $<0.001$ \\
\hline \multicolumn{5}{|l|}{ Left heart metrics } \\
\hline LA area $\left(\mathrm{mm}^{2}\right)$ & 1967 (479) & $2095(632)$ & $2165(768)$ & 0.47 \\
\hline LV chamber area $\left(\mathrm{mm}^{2}\right)$ & $2256(656)$ & $2405(707)$ & $2123(704)$ & 0.002 \\
\hline LV muscle area $\left(\mathrm{mm}^{2}\right)$ & $1549(357)$ & $1618(396)$ & $1586(450)$ & 0.584 \\
\hline \multicolumn{5}{|l|}{ Ratios } \\
\hline $\mathrm{RA}$ area/LA area ratio & $1.0(0.3)$ & $1.1(0.39)$ & $1.6(1.46)$ & 0.003 \\
\hline $\mathrm{RV}$ diameter/LV diameter & $1.0(0.2)$ & $0.95(0.25)$ & $1.33(0.46)$ & $<0.001$ \\
\hline $\mathrm{RV}$ muscle area/LV muscle area & $0.16(0.08)$ & $0.17(0.77)$ & $0.28(0.14)$ & $<0.001$ \\
\hline $\begin{array}{l}\mathrm{RV} \text { chamber area/LV chamber } \\
\text { area }\end{array}$ & $1.0(0.3)$ & $0.99(0.38)$ & $1.56(0.75)$ & $<0.001$ \\
\hline \multicolumn{5}{|l|}{ Vessel measurements } \\
\hline Main PA diameter (mm) & $26(4)$ & $26(4.0)$ & $33(5.3)$ & 0.07 \\
\hline $\begin{array}{l}\text { Main PA/ascending aorta ratio } \\
\text { (ratio) }\end{array}$ & $0.84(0.13)$ & $0.87(0.17)$ & $1.05(0.19)$ & $<0.001$ \\
\hline $\begin{array}{l}\text { Main PA/descending aorta ratio } \\
\text { (ratio) }\end{array}$ & $1.17(0.20)$ & $1.2(0.22)$ & $1.43(0.30)$ & $<0.001$ \\
\hline Left PA diameter (mm) & $21.1(4.1)$ & $22(3.6)$ & $25(3.7)$ & $<0.001$ \\
\hline Right PA diameter $(\mathrm{mm})$ & $21.9(4.3)$ & $22(4.4)$ & $26(4.4)$ & $<0.001$ \\
\hline Inferior vena cava area $\left(\mathrm{mm}^{2}\right)$ & $525(144)$ & 579 (209) & $639(207)$ & 0.023 \\
\hline Superior vena cava area $\left(\mathrm{mm}^{2}\right)$ & $305(80)$ & $320(104)$ & $382(134)$ & $<0.001$ \\
\hline $\begin{array}{l}\text { Hepatic reflux of contrast (score } \\
0 \text { to } 3 \text { ) }\end{array}$ & $\begin{array}{l}0(18), 1(13), 2(3) \\
3(1)\end{array}$ & $\begin{array}{l}0(35), 1(24), 2(7) \\
\text { and } 3(4)\end{array}$ & $\begin{array}{l}0(128), 1(117), 2(98) \\
\text { and } 3(73)\end{array}$ & $<0.001$ \\
\hline
\end{tabular}

$B S A$, body surface area; $W H O F C$, World Health Organisation functional class; $m R A P$, mean right atrial pressure; $m P A P$, mean pulmonary arterial pressure; $P A W P$, pulmonary arterial wedge pressure; $P V R$, pulmonary vascular resistance; $R A$, right atrium; $R V$, right ventricle; $L A$, left atrium; $L V$, left ventricle; $P A$, pulmonary artery 
Fig. 2 Correlations of mean pulmonary arterial pressure with main pulmonary artery diameter (a), right ventricular outflow tract thickness (RVOT) (b), interventricular septal angle (c), left ventricular (LV) area (d) and RV/LV diameter ratio (e). f Correlation between septal angle and RV/LV diameter ratio
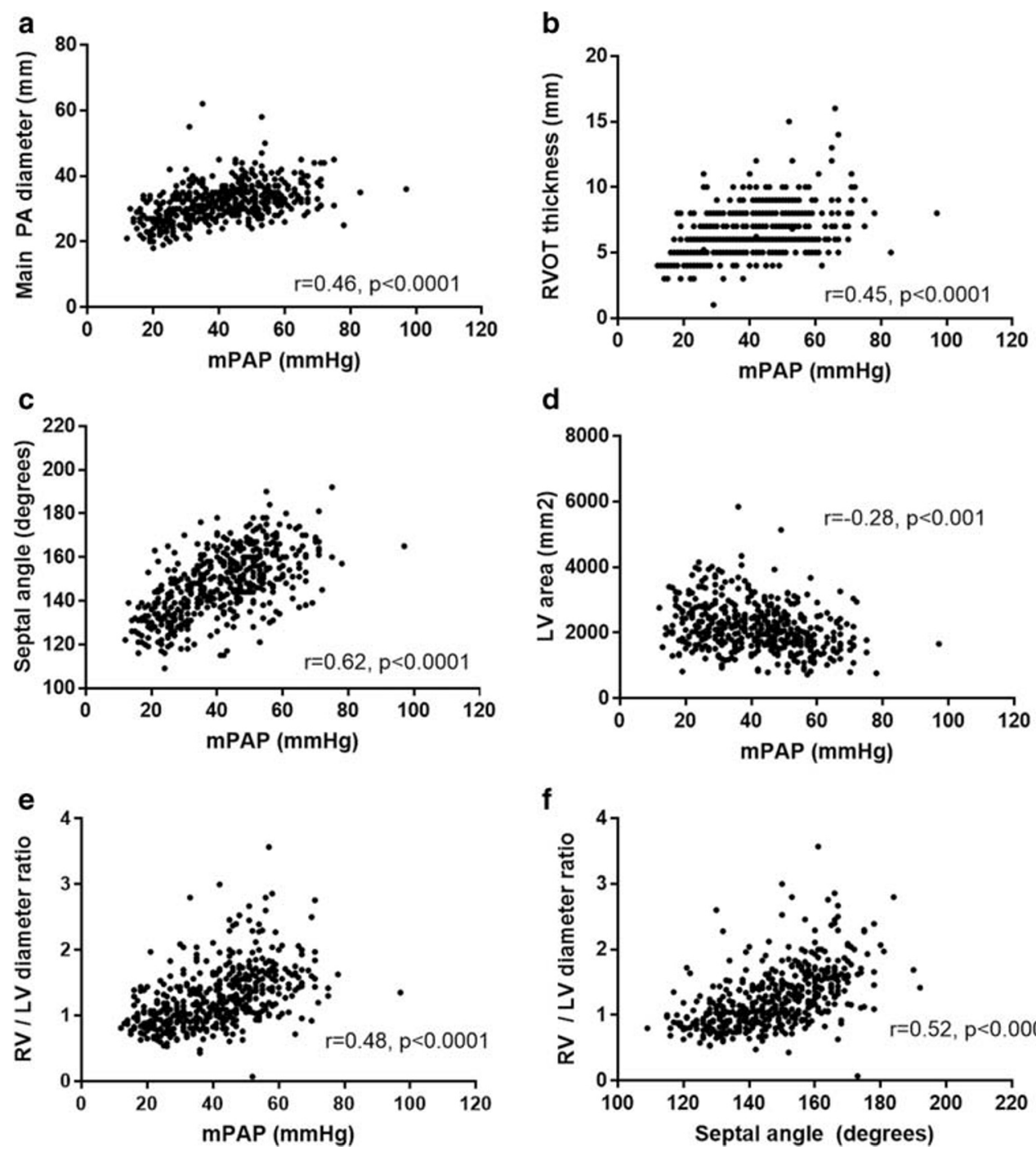

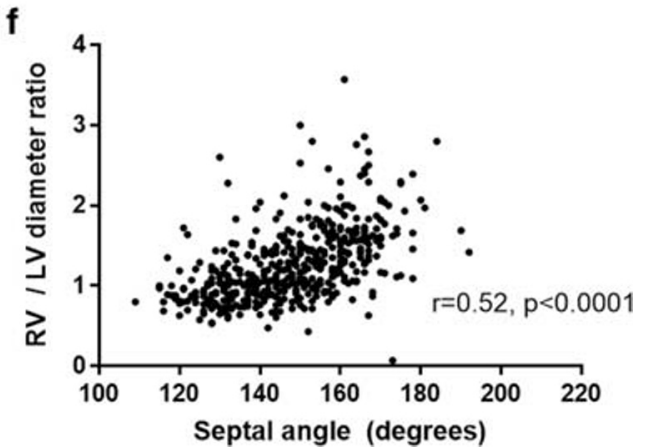

\section{Validation cohort}

\section{Identification of patients with mPAP greater than or equal to $25 \mathrm{mmHg}$}

CT diagnostic model A In the validation cohort, the CT diagnostic model A showed high diagnostic accuracy for the detection of PH (AUC at 0.94; Fig. 3). The CT diagnostic model A adjusted for BSA did not improve the diagnostic performance of the model (AUC 0.92). Sensitivity, specificity and positive and negative predictive values are presented for high sensitivity, specificity and compromise thresholds in Table 3.

CT diagnostic model B Model B was derived excluding the single parameter that required reconstruction (interventricular septal angle). In the validation cohort, diagnostic CT model B had an accuracy of 0.92. Table 3 details the sensitivity, specificity and positive and negative predictive values for high sensitivity, specificity and compromise thresholds.

\section{Identification of patients with mPAP greater than $20 \mathrm{mmHg}$}

CT diagnostic model A In the validation cohort, the CT diagnostic model A showed high diagnostic accuracy for the detection of PH (AUC at 0.91). The CT diagnostic model A adjusted for BSA marginally improved the diagnostic performance of the model (AUC 0.93).

CT diagnostic model B Model B was derived excluding the single parameter that required reconstruction (interventricular septal angle). In the validation cohort, diagnostic CT model B was marginally weaker than model A with an accuracy of 0.87 .

Table 4 details the sensitivity, specificity and positive and negative predictive values for high sensitivity, specificity and 
Table 2 Diagnostic accuracy of predictive thresholds for PA diameter, RVOT thickness, septal angle and RV diameter/LV diameter ratio in the validation cohort

\begin{tabular}{|c|c|c|c|c|c|}
\hline Thresholds & Sensitivity & Specificity & $\begin{array}{l}\text { Positive predictive } \\
\text { value }\end{array}$ & $\begin{array}{l}\text { Negative predictive } \\
\text { value }\end{array}$ & $p$ value \\
\hline \multicolumn{6}{|l|}{ PA diameter } \\
\hline Sensitive $\geq 28 \mathrm{~mm}$ & 90 & 71 & 95 & 50 & $<0.001$ \\
\hline $\begin{array}{l}\text { Compromise } \\
\geq 30 \mathrm{~mm}\end{array}$ & 75 & 81 & 96 & 32 & $<0.001$ \\
\hline Specific $\geq 32 \mathrm{~mm}$ & 58 & 90 & 98 & 24 & $<0.001$ \\
\hline \multicolumn{6}{|l|}{ RVOT thickness } \\
\hline Sensitive $\geq 5 \mathrm{~mm}$ & 95 & 42 & 92 & 57 & $<0.001$ \\
\hline $\begin{array}{l}\text { Compromise } \\
\geq 6 \mathrm{~mm}\end{array}$ & 80 & 77 & 96 & 36 & $<0.001$ \\
\hline Specific $\geq 7 \mathrm{~mm}$ & 55 & 97 & 99 & 24 & $<0.001$ \\
\hline \multicolumn{6}{|l|}{ Septal angle } \\
\hline Sensitive $\geq 130$ & 93 & 35 & 91 & 42 & $<0.001$ \\
\hline $\begin{array}{l}\text { Compromise } \\
\geq 140\end{array}$ & 78 & 97 & 99 & 39 & $<0.001$ \\
\hline Specific $\geq 150$ & 51 & 97 & 99 & 22 & $<0.001$ \\
\hline \multicolumn{6}{|c|}{ RV diameter/LV diameter } \\
\hline Sensitive $\geq 0.8$ & 89 & 19 & 88 & 20 & 0.2375 \\
\hline Compromise $\geq 1$ & 72 & 58 & 92 & 24 & 0.0015 \\
\hline Specific $\geq 1.2$ & 50 & 90 & 97 & 21 & $<0.001$ \\
\hline
\end{tabular}

$P A$, pulmonary artery; $R V O T$, right ventricle outflow tract; $R V$, right ventricle; $L V$, left ventricle
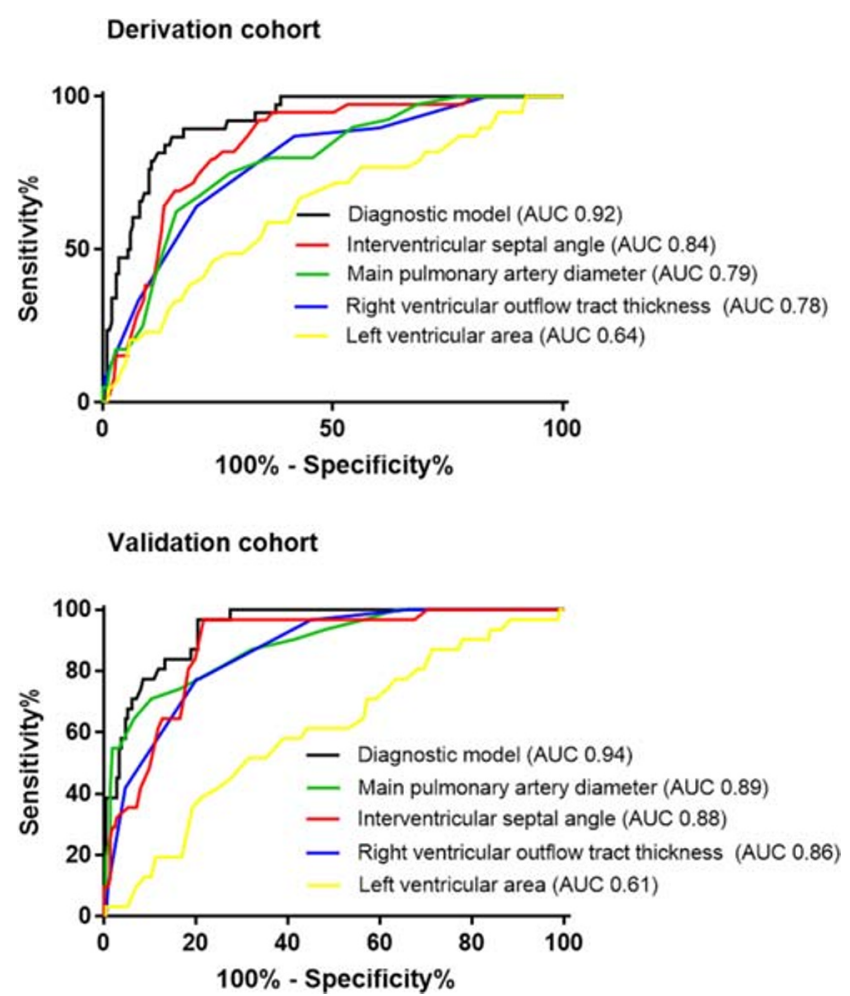

Fig. 3 Receiver operating characteristic analysis in a derivation cohort and validation cohort for diagnostic model $\mathrm{A}$ for prediction of $\mathrm{mPAP} \geq$ $25 \mathrm{mmHg}$ compromise thresholds for identification of patients with mPAP greater than or equal to $20 \mathrm{mmHg}$.

\section{Prognostic significance of $\mathrm{CT}$ and right heart catheterisation thresholds}

CT diagnostic model A In the validation cohort, 93 patients died; mean follow-up was 42 months. The CT diagnostic model A sensitive (0), compromise (1.25) and (2.5) specific thresholds for $\mathrm{mPAP} \geq 25 \mathrm{mmHg}$ were strongly predictive of mortality log rank 11.13 ( $p=0.0009$ and 9.70; $p=0.002$ and 9.49; $p=0.002$ respectively). The $\mathrm{CT}$ diagnostic model A sensitive (0), compromise (1.0) and (2.25) specific thresholds for mPAP $>20 \mathrm{mmHg}$ were also strongly predictive of mortality log rank $11.13(p=0.0009$ and $6.25 ; p=0.010$ and $10.57 ; p=0.001)$.

CT diagnostic model B The CT diagnostic model B sensitive (0.5), compromise (1.0) and (1.5) specific thresholds for mPAP $\geq 25 \mathrm{mmHg}$ were as follows (mortality log rank 6.92): $p=0.009$ and $3.25 ; p=0.071$ and $6.28 ; p=0.012$ respectively. The CT diagnostic model B sensitive (0.5), compromise (0.8) and (1.4) specific thresholds for mPAP $>20 \mathrm{mmHg}$ were also strongly predictive of mortality log rank $6.92(p=0.009$ and $6.56 ; p=0.010$ and $535 ; p=0.021)$.

At Cox regression analysis, $\mathrm{CT}$ diagnostic models A and B were prognostic; $z$ score hazard ratios were 1.56 and 1.42 , both $p<0.0001$. 
Table 3 Regression CT diagnostic models A and B thresholds and their accuracy for predicting the presence of PH in the validation cohort

\begin{tabular}{|c|c|c|c|c|c|}
\hline Thresholds & Sensitivity & Specificity & Positive predictive value & Negative predictive value & $p$ value \\
\hline \multicolumn{6}{|l|}{ Diagnostic model A } \\
\hline Sensitive $\geq 0$ units & 96 & 58 & 94 & 69 & $<0.001$ \\
\hline Compromise $\geq 1.25$ units & 82 & 84 & 97 & 41 & $<0.001$ \\
\hline Specific $\geq 2.5$ units & 71 & 100 & 100 & 33 & $<0.001$ \\
\hline \multicolumn{6}{|l|}{ Diagnostic model B } \\
\hline Sensitive $\geq 0.5$ units & 92 & 71 & 96 & 55 & $<0.001$ \\
\hline Compromise $\geq 1$ units & 84 & 81 & 97 & 42 & $<0.001$ \\
\hline Specific $\geq 1.5$ units & 75 & 90 & 98 & 35 & $<0.001$ \\
\hline
\end{tabular}

Right heart catheter diagnostic thresholds RHC diagnostic thresholds $\geq 25 \mathrm{mmHg}$ and $>20 \mathrm{mmHg}$ were not prognostic in this cohort (log rank 2.86, $p=0.09$ and $\log$ rank 1.77, $p=$ 0.18 respectively; see Fig. 4).

\section{Correlations and diagnostic value of individual CT metrics with pulmonary haemodynamics and MRI metrics in the full cohort}

Correlations between $\mathrm{CT}$ vascular and cardiac measures are shown in Supplementary Table 1. Figure 2 shows the correlation of CT metrics and mean pulmonary artery pressure. A detailed description of the MRI findings is found in Supplementary Results.

\section{Reproducibility}

High reproducibility of interventricular septal angle (ICC 0.921 ), pulmonary artery diameter (ICC 0.954 ) and left ventricular area (ICC 0.953) was demonstrated. In comparison, good reproducibility was recorded for the variables RV/LV diameter ratio (ICC 0.810 ) and right ventricular outflow tract thickness (ICC 0.76) (see Table 5).

\section{Discussion}

In this study, we have shown that CT diagnostic models combining multiple metrics are superior to individual metrics in predicting the likelihood of $\mathrm{PH}$. We have created models that utilise axial and reconstructed images and have also developed pragmatic scoring systems based on axial only images to improve the accessibility of CT to both radiologists and physicians. This approach could be used to increase or reduce the pre-test probability of $\mathrm{PH}$. In addition, the $\mathrm{CT}$ diagnostic model had prognostic value with a negative score particularly at the sensitive threshold, indicating excellent survival.

Regression analysis identified pulmonary artery diameter, right ventricular outflow tract thickness, left ventricular area and interventricular septal angle as having additive value for the diagnosis of $\mathrm{PH}$ (CT diagnostic model A). Using a threshold of $\geq 0$ units had a sensitivity of $96 \%$ and specificity of $58 \%$, whereas a threshold of $\geq 2.5$ units had a sensitivity of $71 \%$ and specificity of $100 \%$ in the validation cohort. An alternative model (CT diagnostic model B), utilising measurements from axial images alone, pulmonary artery diameter, right ventricular outflow tract thickness and the RV/LV diameter ratio, although marginally weaker also had good diagnostic accuracy. This model may provide a practical alternative if

Table 4 Regression CT diagnostic models A and B thresholds and their accuracy for predicting the presence of patients with mPAP greater than $20 \mathrm{mmHg}$ in the validation cohort

\begin{tabular}{|c|c|c|c|c|c|}
\hline Thresholds & Sensitivity & Specificity & $\begin{array}{l}\text { Positive predictive } \\
\text { value }\end{array}$ & $\begin{array}{l}\text { Negative predictive } \\
\text { value }\end{array}$ & $p$ value \\
\hline \multicolumn{6}{|l|}{ Diagnostic model A } \\
\hline Sensitive $\geq 0$ units & 93 & 67 & 98 & 38 & $<0.001$ \\
\hline Compromise $\geq 1$ units & 82 & 80 & 98 & 22 & $<0.001$ \\
\hline Specific $\geq 2.25$ units & 67 & 100 & 100 & 17 & $<0.001$ \\
\hline \multicolumn{6}{|l|}{ Diagnostic model B } \\
\hline Sensitive $\geq 0.5$ units & 87 & 67 & 98 & 25 & $<0.001$ \\
\hline Compromise $\geq 0.8$ units & 82 & 90 & 98 & 23 & $<0.001$ \\
\hline Specific $\geq 1.4$ units & 72 & 80 & 98 & 16 & $<0.001$ \\
\hline
\end{tabular}


Fig. 4 Prognostic significance of CT model A showing CT thresholds ((a) sensitive threshold and (b) compromise threshold) and mPAP thresholds ((c) mPAP $\geq 25 \mathrm{mmHg}$ and (d) $\mathrm{mPAP}>$ $20 \mathrm{mmHg}$ ) a

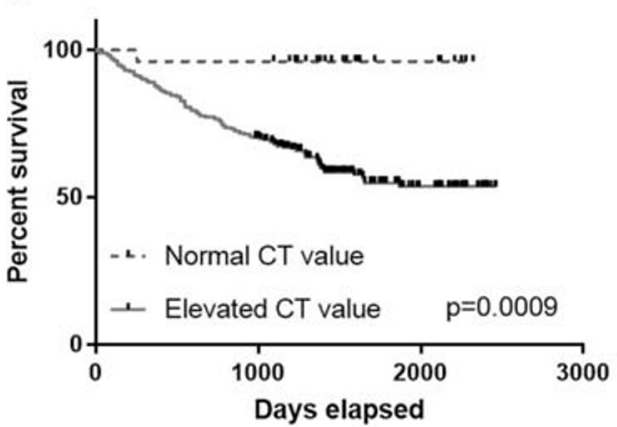

c $\mathrm{PH}$ or $\mathrm{No} \mathrm{PH}$ mPAP $\geq \mathbf{2 5 \mathrm { mmHg }}$

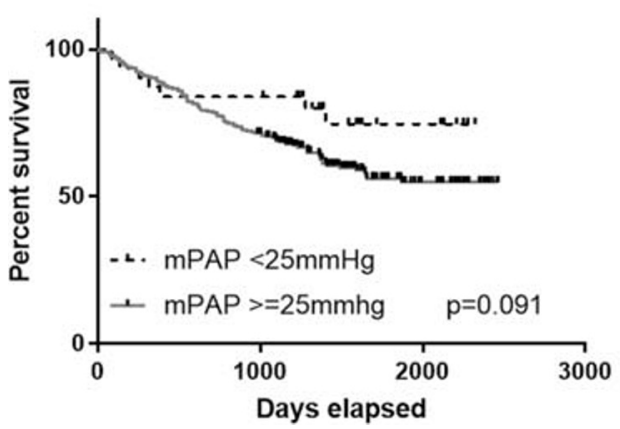

CT model compromise threshold
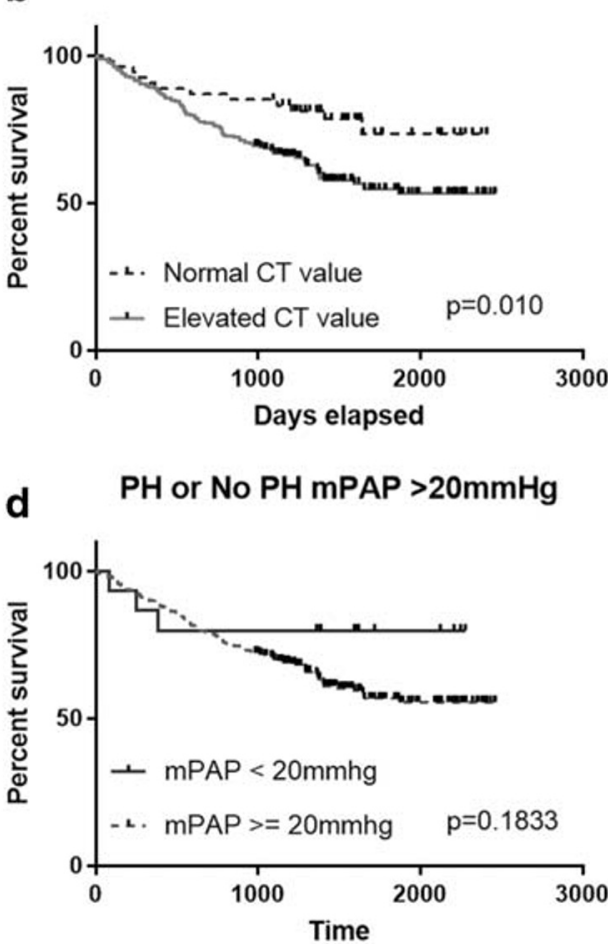

reconstruction tools are not available when reviewing CT images. In this model, a score of $\geq 0.5$ units had a sensitivity of $92 \%$ and specificity of $71 \%$, whereas a score of $\geq 1.5$ units had a sensitivity of $75 \%$ and specificity of $90 \%$.

The most commonly measured vessel on CT pulmonary angiograms in suspected PH is the pulmonary artery. The Framingham study established a reference range for normal and established $27 \mathrm{~mm}$ and $29 \mathrm{~mm}$ as representing the upper limits of normal for female and male patients, respectively. Previous studies using pulmonary artery size to diagnose $\mathrm{PH}$ have shown that a pulmonary artery diameter greater than $29 \mathrm{~mm}$ had a sensitivity of $75 \%$ and specificity of $89 \%$ for the presence of $\mathrm{PH}$ [29]. The utility of measuring the main pulmonary artery diameter and the pulmonary artery to aortic ratio has also been studied in suspected $\mathrm{PH}$. $\mathrm{Ng}$ et al found that a pulmonary artery to aortic ratio $>1$ was $92 \%$ specific for a mPAP > $20 \mathrm{mmHg}$ [30]; other reports indicate diagnostic value in suspected $\mathrm{PH}[31,32]$. However, the pulmonary artery may be enlarged in the absence of $\mathrm{PH}$ and increases in pulmonary artery size over time are a feature of $\mathrm{PH}$ and are not necessarily an indication of increasing pulmonary artery pressure; as such, the correlation with mPAP is weak [33]. Although some investigators have suggested that pulmonary artery diameter may be unreliable in patients with underlying interstitial lung disease [34], we have recently shown that PA size has equivalent diagnostic utility in all patients with suspected PH and interstitial lung disease [35]. The present study confirms pulmonary artery diameter as an independent predictor of the presence of $\mathrm{PH}$. We identified three thresholds: $\geq 28 \mathrm{~mm}$ as sensitive, $\geq 30 \mathrm{~mm}$ as a compromise and $\geq$ $32 \mathrm{~mm}$ as a specific threshold. These three thresholds can be used depending on the clinical scenario. Of CT measures used, the pulmonary artery diameter was the most reproducible. PA diameter, however, did not prove to be a significant independent predictor of patients with $\mathrm{PH}$ defined by $\mathrm{mPAP} \geq$ $20 \mathrm{mmHg}$. We suspect this is due to underpowering based on
Table 5 Reproducibility tests of the variables selected in model

\begin{tabular}{llllr}
\hline Covariates & Intra-class correlation & Upper 95\% CI & Lower 95\% CI & $p$ value \\
\hline Septal angle & 0.921 & 0.973 & 0.769 & $<0.001$ \\
PA diameter & 0.954 & 0.988 & 0.710 & $<0.001$ \\
RV outflow tract & 0.760 & 0.920 & 0.263 & 0.007 \\
LV area & 0.953 & 0.984 & 0.862 & $<0.001$ \\
RV/LV diameter ratio & 0.810 & 0.447 & 0.936 & 0.002 \\
\hline
\end{tabular}

$P A$, pulmonary artery; $R V$, right ventricle; $L V$, left ventricle 
the small number of patients with $\mathrm{mPAP}<20 \mathrm{mmHg}$; further work in populations with larger number of patients with mild disease is required to better develop a predictive model for identification of patients with $\mathrm{mPAP} \geq 20 \mathrm{mmHg}$.

Interventricular septal angle also showed strong diagnostic value and, when increased, had high specificity for the presence of $\mathrm{PH}$. In the present study, CT images were reconstructed into the short-axis plane and a moderate correlation was identified with mPAP $(r=0.62)$, though weaker than that identified previously using MRI-derived systolic septal angle $(r=0.82)$ [36]. However, in this population, the diagnostic accuracy of CT septal angle was similar to that of MRI-derived systolic septal angle [11], which was an unexpected finding given the non-gated nature of CT. This may reflect the impact of RV enlargement and pressure overload both in diastole and systole which is seen frequently in the setting of significant pre-capillary disease. However, gating may be more important when minor elevations of pulmonary artery pressure are being investigated. Min et al also studied CT septal angle using ungated CT pulmonary angiography demonstrating a close correlation with pulmonary vascular resistance with high accuracy for detecting elevated PVR [21]. Septal angle may also have a role in the identification of patients with combined pre- and post-capillary $\mathrm{PH}$, which has been demonstrated using MRI [37]. The ratio of the right ventricular to left ventricular diameter has prognostic value in PAH [17] and we have also demonstrated diagnostic value in this study. However, using reconstructed short-axis images to calculate septal angle, rather than using this ratio, improved diagnostic certainty. The ratio of the right ventricular to left ventricular diameter, however, still provides additional diagnostic value when added to pulmonary artery size and right ventricular outflow tract diameter and should be combined with these measures, when images cannot be reconstructed, to improve the diagnostic performance of CT pulmonary angiography.

The musculature of the right ventricular outflow tract is compacted and subjectively easier to measure than the trabeculated right ventricular free wall. Hence, it is not unexpected that the outflow tract thickness had higher diagnostic accuracy. Nonetheless, of all the metrics used in the diagnostic models, the right ventricular outflow tract thickness was the least reproducible. Right ventricular mass measured by MRI has also been shown previously to increase with pulmonary arterial pressure $[9,10]$. This study has also examined the correlation of CT metrics with pulmonary haemodynamics. Septal angle had the highest correlation with mean pulmonary artery pressure of any of the CT metrics $(r=0.62)$ and was superior to $\mathrm{RV} / \mathrm{LV}$ diameter ratio, demonstrating the value of reconstructing images.

\section{Limitations}

The CT scans were not cardiac-gated, but despite this, CT measurements still had diagnostic value. Cardiac-gated CT allows for imaging of specific stages during a cardiac cycle and reduces cardiac motion artefacts seen in a CTPA and would help capture maximal deviation of the interventricular septum and volumetric metrics in future studies. Positive and negative predictive values will differ depending on the diagnostic setting; here, we show data from a tertiary referral centre population of patients with $\mathrm{PH}$ with a high pre-test probability of $\mathrm{PH}$. This data may be particularly helpful when triaging patients with suspected severe PH for consideration of targeted pulmonary vascular therapies, although the diagnostic performance of $\mathrm{CT}$ in a community diagnostic setting has not been assessed.

\section{Conclusions}

This study has developed and validated predictive thresholds using a combination of CT metrics in separate derivation and validation cohorts. Sensitive and specific thresholds have been identified that may be of value in both screening and for more definitive diagnosis depending on the clinical scenario. The diagnostic CT thresholds are also of prognostic value; patients found not to have PH on CT have an excellent outcome. Given the widespread use of CT to investigate unexplained breathlessness, a more systematic approach to CT evaluation may improve $\mathrm{PH}$ diagnostic rates.

Funding information This study has received funding from Wellcome Trust (205188/Z/16/Z), NIHR (NIHR - RP-R3-12-027) and MRC (MR/M008894/1) POLARIS. Bayer support DC.

\section{Compliance with ethical standards}

Guarantor The scientific guarantor of this publication is Dr. Andy Swift.

Conflict of interest The authors of this manuscript declare no relationships with any companies whose products or services may be related to the subject matter of the article.

Statistics and biometry One of the authors has significant statistical expertise.

Informed consent Written informed consent was waived by the Institutional Review Board.

Ethical approval Institutional Review Board approval was obtained.

Study subjects or cohorts overlap Some study subjects or cohorts have been previously reported in papers asking different clinical questions:

Currie BJ, Johns C, Chin M et al (2018) CT derived left atrial size identifies left heart disease in suspected pulmonary hypertension: Derivation and validation of predictive thresholds. Int J Cardiol 260:172-177.

Methodology

- Retrospective

- Diagnostic or prognostic study

- Performed at one institution 
Open Access This article is licensed under a Creative Commons Attribution 4.0 International License, which permits use, sharing, adaptation, distribution and reproduction in any medium or format, as long as you give appropriate credit to the original author(s) and the source, provide a link to the Creative Commons licence, and indicate if changes were made. The images or other third party material in this article are included in the article's Creative Commons licence, unless indicated otherwise in a credit line to the material. If material is not included in the article's Creative Commons licence and your intended use is not permitted by statutory regulation or exceeds the permitted use, you will need to obtain permission directly from the copyright holder. To view a copy of this licence, visit http://creativecommons.org/licenses/by/4.0/.

\section{References}

1. Galie N, Humbert M, Vachiery JL et al (2016) 2015 ESC/ERS guidelines for the diagnosis and treatment of pulmonary hypertension: the Joint Task Force for the Diagnosis and Treatment of Pulmonary Hypertension of the European Society of Cardiology (ESC) and the European Respiratory Society (ERS): endorsed by: Association for European Paediatric and Congenital Cardiology (AEPC), International Society for Heart and Lung Transplantation (ISHLT). Eur Heart J 37:67-119

2. Kovacs G, Berghold A, Scheidl S, Olschewski H (2009) Pulmonary arterial pressure during rest and exercise in healthy subjects: a systematic review. Eur Respir J 34:888-894

3. Kiely DG, Elliot CA, Sabroe I, Condliffe R (2013) Pulmonary hypertension: diagnosis and management. BMJ 346:f2028

4. Kiely DG, Levin D, Hassoun P et al (2019) EXPRESS: statement on imaging and pulmonary hypertension from the Pulmonary Vascular Research Institute (PVRI). Pulm Circ. https://doi.org/10. 1177/2045894019841990:2045894019841990

5. Taleb M, Khuder S, Tinkel J, Khouri SJ (2013) The diagnostic accuracy of Doppler echocardiography in assessment of pulmonary artery systolic pressure: a meta-analysis. Echocardiography 30 : 258-265

6. Arcasoy SM, Christie JD, Ferrari VA et al (2003) Echocardiographic assessment of pulmonary hypertension in patients with advanced lung disease. Am J Respir Crit Care Med 167: 735-740

7. Rich JD, Shah SJ, Swamy RS, Kamp A, Rich S (2011) Inaccuracy of Doppler echocardiographic estimates of pulmonary artery pressures in patients with pulmonary hypertension: implications for clinical practice. Chest 139:988-993

8. Strange G, Stewart S, Celermajer DS et al (2019) Threshold of pulmonary hypertension associated with increased mortality. J Am Coll Cardiol 73:2660-2672

9. Saba TS, Foster J, Cockburn M, Cowan M, Peacock AJ (2002) Ventricular mass index using magnetic resonance imaging accurately estimates pulmonary artery pressure. Eur Respir J 20:1519-1524

10. Swift AJ, Rajaram S, Condliffe R et al (2012) Diagnostic accuracy of cardiovascular magnetic resonance imaging of right ventricular morphology and function in the assessment of suspected pulmonary hypertension results from the ASPIRE registry. J Cardiovasc Magn Reson 14:40

11. Johns CS, Kiely DG, Rajaram S et al (2019) Diagnosis of pulmonary hypertension with cardiac MRI: derivation and validation of regression models. Radiology 290:61-68

12. Gan CT, Lankhaar JW, Westerhof $N$ et al (2007) Noninvasively assessed pulmonary artery stiffness predicts mortality in pulmonary arterial hypertension. Chest 132:1906-1912
13. Sanz J, Kariisa M, Dellegrottaglie S et al (2009) Evaluation of pulmonary artery stiffness in pulmonary hypertension with cardiac magnetic resonance. JACC Cardiovasc Imaging 2:286-295

14. Sanz J, Kuschnir P, Rius T et al (2007) Pulmonary arterial hypertension: noninvasive detection with phase-contrast MR imaging. Radiology 243:70-79

15. Lungu A, Swift AJ, Capener D, Kiely D, Hose R, Wild JM (2016) Diagnosis of pulmonary hypertension from magnetic resonance imaging-based computational models and decision tree analysis. Pulm Circ 6:181-190

16. Geyer LL, Schoepf UJ, Meinel FG et al (2015) State of the art: iterative CT reconstruction techniques. Radiology 276:339-357

17. Condliffe R, Radon M, Hurdman J et al (2011) CT pulmonary angiography combined with echocardiography in suspected systemic sclerosis-associated pulmonary arterial hypertension. Rheumatology (Oxford) 50:1480-1486

18. Rajaram S, Swift AJ, Condliffe R et al (2015) CT features of pulmonary arterial hypertension and its major subtypes: a systematic CT evaluation of 292 patients from the ASPIRE Registry. Thorax 70:382-387

19. Spruijt OA, Bogaard HJ, Heijmans MW et al (2015) Predicting pulmonary hypertension with standard computed tomography pulmonary angiography. Int J Cardiovasc Imaging 31:871-879

20. Shen Y, Wan C, Tian P et al (2014) CT-base pulmonary artery measurement in the detection of pulmonary hypertension: a metaanalysis and systematic review. Medicine (Baltimore) 93:e256

21. Liu M, Ma ZH, Guo XJ et al (2012) A septal angle measured on computed tomographic pulmonary angiography can noninvasively estimate pulmonary vascular resistance in patients with chronic thromboembolic pulmonary hypertension. J Thorac Imaging 27: 325-330

22. McCann C, Gopalan D, Sheares K, Screaton N (2012) Imaging in pulmonary hypertension, part 1: clinical perspectives, classification, imaging techniques and imaging algorithm. Postgrad Med J 88: 271-279

23. Currie BJ, Johns C, Chin M et al (2018) CT derived left atrial size identifies left heart disease in suspected pulmonary hypertension: derivation and validation of predictive thresholds. Int J Cardiol 260: 172-177

24. Renapurkar RD, Shrikanthan S, Heresi GA, Lau CT, Gopalan D (2017) Imaging in chronic thromboembolic pulmonary hypertension. J Thorac Imaging 32:71-88

25. Rajaram S, Swift AJ, Capener D et al (2012) Comparison of the diagnostic utility of cardiac magnetic resonance imaging, computed tomography, and echocardiography in assessment of suspected pulmonary arterial hypertension in patients with connective tissue disease. J Rheumatol 39:1265-1274

26. Klok FA, Van Der Bijl N, Eikenboom HC et al (2010) Comparison of $\mathrm{CT}$ assessed right ventricular size and cardiac biomarkers for predicting short-term clinical outcome in normotensive patients suspected of having acute pulmonary embolism. J Thromb Haemost 8:853-856

27. Collins MA, Pidgeon JW, Fitzgerald R (1995) Computed tomography manifestations of tricuspid regurgitation. Br J Radiol 68:10581060

28. Hurdman J, Condliffe R, Elliot CA et al (2012) ASPIRE registry: assessing the Spectrum of Pulmonary hypertension Identified at a REferral centre. Eur Respir J 39:945-955

29. Tan RT, Kuzo R, Goodman LR, Siegel R, Haasler GB, Presberg KW (1998) Utility of CT scan evaluation for predicting pulmonary hypertension in patients with parenchymal lung disease. Medical College of Wisconsin Lung Transplant Group. Chest 113:1250 1256

30. Ng CS, Wells AU, Padley SP (1999) A CT sign of chronic pulmonary arterial hypertension: the ratio of main pulmonary artery to aortic diameter. J Thorac Imaging 14:270-278 
31. Devaraj A, Wells AU, Meister MG, Corte TJ, Wort SJ, Hansell DM (2010) Detection of pulmonary hypertension with multidetector CT and echocardiography alone and in combination. Radiology 254: 609-616

32. Edwards PD, Bull RK, Coulden R (1998) CT measurement of main pulmonary artery diameter. Br J Radiol 71:1018-1020

33. Boerrigter B, Mauritz GJ, Marcus JT et al (2010) Progressive dilatation of the main pulmonary artery is a characteristic of pulmonary arterial hypertension and is not related to changes in pressure. Chest 138:1395-1401

34. Devaraj A, Wells AU, Meister MG, Corte TJ, Hansell DM (2008) The effect of diffuse pulmonary fibrosis on the reliability of CT signs of pulmonary hypertension. Radiology 249:1042-1049

35. Chin M, Johns C, Currie BJ et al (2018) Pulmonary artery size in interstitial lung disease and pulmonary hypertension: association with interstitial lung disease severity and diagnostic utility. Front Cardiovasc Med 5:53

36. Swift AJ, Rajaram S, Hurdman J et al (2013) Noninvasive estimation of PA pressure, flow, and resistance with CMR imaging: derivation and prospective validation study from the ASPIRE Registry. JACC Cardiovasc Imaging 6:1036-1047

37. Johns CS, Wild JM, Rajaram S et al (2018) Identifying at-risk patients with combined pre- and postcapillary pulmonary hypertension using interventricular septal angle at cardiac MRI. Radiology 289:61-68

Publisher's note Springer Nature remains neutral with regard to jurisdictional claims in published maps and institutional affiliations. 